\title{
Perinatal Exposure to an Environmentally Relevant Mixture of Phthalates Results in a Lower Number of Neurons and Synapses in the Medial Prefrontal Cortex and Decreased Cognitive Flexibility in Adult Male and Female Rats
}

\author{
Daniel G. Kougias, ${ }^{2}$ Elli P. Sellinger, ${ }^{2}$ 익i Willing, ${ }^{1}$ and Janice M. Juraska ${ }^{1,2}$ \\ ${ }^{1}$ Department of Psychology and ${ }^{2}$ Neuroscience Program, University of Illinois, Champaign, Illinois 61820
}

The growth and organization of the developing brain are known to be influenced by hormones, but little is known about whether disruption of hormones affects cortical regions, such as $\mathrm{mPFC}$. This region is particularly important given its involvement in executive functions and implication in the pathology of many neuropsychiatric disorders. Here, we examine the long-term effects of perinatal exposure to endocrine-disrupting compounds, the phthalates, on the mPFC and associated behavior. This investigation is pertinent as humans are ubiquitously exposed to phthalates through a variety of consumer products and phthalates can readily cross the placenta and be delivered to offspring via lactation. Pregnant dams orally consumed an environmentally relevant mixture of phthalates at 0,200 , or $1000 \mu \mathrm{g} / \mathrm{kg} / \mathrm{d}$ through pregnancy and for $10 \mathrm{~d}$ while lactating. As adults, offspring were tested in an attentional set-shifting task, which assesses cognitive flexibility. Brains were also examined in adulthood for stereological quantification of the number of neurons, glia, and synapses within the mPFC. We found that, independent of sex, perinatal phthalate exposure at either dose resulted in a reduction in neuron number, synapse number, and size of the $\mathrm{mPFC}$ and a deficit in cognitive flexibility. Interestingly, the number of synapses was correlated with cognitive flexibility, such that rats with fewer synapses were less cognitively flexible than those with more synapses. These results demonstrate that perinatal phthalate exposure can have long-term effects on the cortex and behavior of both male and female rats.

Key words: attentional set shift; endocrine disruptor; mPFC; neuron number; phthalates; synapse number

\section{Significance Statement}

Humans globally are exposed on a daily basis to a variety of phthalates, which are endocrine-disrupting chemicals. The effects of phthalate exposure on the developing brain, especially on cognitively relevant regions, such as the mPFC, are not known. Here, we use a rat model of human prenatal exposure to an environmentally relevant mixture of phthalates and find that there is an appreciable reduction in neuron number, synapse number, and size of the mPFC and a deficit in cognitive flexibility. These results may have serious implications for humans given that the MPFC is involved in executive functions and is implicated in the pathology of many neuropsychiatric disorders.

\section{Introduction}

The growth and organization of the developing brain are influenced by hormones. Indeed, gonadal hormones play a critical

\section{Received March 5, 2018; revised May 22, 2018; accepted June 12, 2018.}

Author contributions: D.G.K. wrote the first draft of the paper; J.W. and J.M.J. edited the paper. D.G.K. and J.M.J. designed research; D.G.K., E.P.S., and J.W. performed research; D.G.K. and E.P.S. analyzed data.

This work was supported by National Institute of Environmental Health Sciences Grant P01 ES002848-Project 3 to J.M.J., U.S. Environmental Protection Agency Grant 83543401 Project 3 to J.M.J., and National Institute of Environmental Health Sciences Grant T32 ES007326 to D.G.K. This work was conducted in part at the Microscopy Suite of the Beckman Institute for Advanced Science and Technology at the University of Illinois at Urbana-Champaign. We thank Laura Cortes, Steven Rhoads, Anthony Franceschelli, and the Animal Care staff in Psychology for assistance.

The authors declare no competing financial interests.

Correspondence should be addressed to Dr. Janice M. Juraska, Department of Psychology, University of Illinois, 603 E. Daniel Street, Champaign, IL 61820. E-mail: jjuraska@illinois.edu. role during perinatal development in regulating apoptosis $(\mathrm{Nu}-$ ñez et al., 2000; Forger, 2009) and synaptic number (Nishizuka and Arai, 1981; Pérez et al., 1990; Simerly, 2002). Although much of this work has focused on subcortical regions where sex hormone receptors are particularly abundant, it is known that these receptors are also present during development in other brains areas, including the cerebral cortex (Pérez et al., 2003; Westberry and Wilson, 2012; Tsai et al., 2015).

Because hormones can impact the developing brain, there is a growing scientific concern regarding the influence of environ- 
mental endocrine-disrupting chemicals on neurodevelopment. One such class of chemicals, known as phthalates, is problematic because of their ubiquitous environmental presence. Phthalates, which are often found to be antiandrogenic (Howdeshell et al., 2017), are used as plasticizers in a variety of consumer goods, including plastics, personal care products, fragranced products, pharmaceuticals, clothing, and building materials. Because phthalates are not covalently bound within the matrices of products, they can freely migrate or evaporate out into the environment. Consequently, contact with these products can lead to exposure through transdermal uptake, incidental ingestion, and inhalation. Indeed, diet is presumed to be the main source of exposure to many phthalates due to contamination during production, processing, and packaging of foods (Heudorf et al., 2007).

Considering that phthalates can readily cross the placenta (Mose et al., 2007) and be delivered to offspring via lactation (Lyche et al., 2009), the perinatal period appears to be a particularly vulnerable window to their endocrine-disrupting effects. Indeed, there is indirect evidence that prenatal phthalate exposure, as measured by maternal urinary metabolites, has effects on the developing human brain as exposure has been associated with adverse neurodevelopmental outcomes (Ejaredar et al., 2015). In particular, there are several studies indicating that prenatal phthalate exposure may negatively influence children's behavior, executive function, and incidence of neuropsychiatric disorders (Engel et al., 2010; Swan et al., 2010; Kobrosly et al., 2014; Lien et al., 2015; Jeddi et al., 2016). Although one study found that concurrent phthalate exposure was negatively correlated with cortical thickness in the right middle and superior temporal gyri of children (Park et al., 2015), there is little understanding of potential cellular effects on the developing cortex.

Rodent research on perinatal exposure to a single phthalate has found impairments in water maze performance (e.g., Dai et al., 2015), contextual fear conditioning (DeBartolo et al., 2016), and structural and functional plasticity of the hippocampus (Holahan and Smith, 2015), but no study to date has examined the effect of perinatal phthalate exposure on executive function or the cortex in adulthood. Furthermore, much of the rodent research focuses on exposure to a single phthalate, whereas humans are exposed to many. Thus, further investigation using an environmentally relevant mixture of phthalates is necessary to explore the outcomes of perinatal exposure on executive function and the cortex.

In this study, we use a rat model of human prenatal exposure to investigate the long-lasting effects of an environmentally relevant mixture of phthalates on cognitive flexibility and mPFC neuroanatomy. In particular, cognitive flexibility, which relies on the mPFC (Gruber et al., 2010), was assessed in adulthood using an attentional set-shifting task. Our neuroanatomical investigation focused on the total number of neurons, glia, and synapses within the adult mPFC. The $\mathrm{mPFC}$ is also of special interest given its implication in the pathology of many neuropsychiatric disorders, some of which have been positively associated with prenatal phthalate exposure (Ejaredar et al., 2015).

\section{Materials and Methods}

\section{Subjects}

The animals used in this study and the rearing of litters have been previously described (Kougias et al., 2018). Male $(n=32)$ and female $(n=32)$ Long-Evans hooded rats at $\sim 3$ months of age were obtained from Harlan Laboratories (now Envigo) and housed for a minimum of 2 weeks before being paired for breeding in five cohorts, each of which contained all of the experimental groups. Rats were housed in same-sex pairs on a $12 \mathrm{~h}$ light/dark cycle with food and water available ad libitum. To reduce exposure to endocrine-disrupting chemicals, all rats were housed in bis- phenol A-free polysulfone cages, fed a low phytoestrogen food (Harlan 2020X; Teklad Diets), and hydrated with reverse osmosis-filtered water in glass bottles. All procedures were approved by the University of Illinois Institutional Care and Use Committee and adhere to the National Institute of Health guidelines on the ethical use of animals.

For breeding, opposite sex pairs were placed in suspended wirebottom cages and inspected daily for sperm plugs, which marked gestational day (GD) 0 . The dams were then housed individually, fed a control diet (D10012G) obtained from Research Diets, and assigned to one of three exposure groups $(n=11,9,11$, respectively): 0,200 , or $1000 \mu \mathrm{g}$ phthalates $/ \mathrm{kg}$ body weight. On the day of birth, designated as postnatal day $(\mathrm{P})$, litters were not disturbed; however, litters were culled to 10 pups each on P1 to control for litter size and sex ratio. The control diet was replaced with the $2020 \times$ feed on P10. Only one pup from each sex within a litter was used for each endpoint (i.e., one male and female within a litter was used for cognitive behavior testing and another male and female from the same litter for neuroanatomical measurements).

On GD0 and GD1, the dams were given half a cookie (Newman's Own, organic alphabet cookie, vanilla flavor) with tocopherol-stripped corn oil pipetted onto it for acclimatization. Starting on GD2 through P10, dams immediately and completely consumed half a cookie overlaid with the daily dose of phthalate mixture at their corresponding concentration, as phthalate exposure can occur through both placental transfer and lactation in rats (Dostal et al., 1987). To avoid direct exposure to pups, the cookie was given to the dams while away from the nest. This method of oral administration is presumably not stressful and is similar to the major route of human exposure to phthalates. Pups were weaned on P25 and pair-housed with similarly aged animals of the same sex and exposure.

\section{Phthalate mixture}

The phthalate mixture was identical to that used by Kougias et al. (2018) The phthalate mixture was derived by back-calculating exposures based on the urinary metabolites of pregnant women in the ChampaignUrbana community (unpublished data), which approximates the U.S. population levels (Corbasson et al., 2016). The phthalate mixture was comprised of 35\% diethyl (DEP), 21\% bis(2-ethylhexyl) (DEHP), 15\% dibutyl (DBP), 15\% di-isononyl (DiNP), 8\% di-isobutyl (DiBP), and 5\% benzyl butyl (BBP) phthalate. The mixture was prepared by suspending $0,0.6$, or $3 \mathrm{mg}$ phthalates $/ \mathrm{ml}$ tocopherol-stripped corn oil to ensure equivalent volume ( $1 \mu \mathrm{l} / 3 \mathrm{~g}$ body weight $)$ in administering the respective 0 (control), 200, or $1000 \mu \mathrm{g}$ phthalates $/ \mathrm{kg}$ doses. These doses are relatively low within the rodent literature; and based on the body surface area normalization method (Reagan-Shaw et al., 2008), which is prescribed by the U.S. Food and Drug Administration, a 200 and $1000 \mu \mathrm{g} / \mathrm{kg}$ dose in rats is equivalent to a human dose of 32.43 and $162.16 \mu \mathrm{g} / \mathrm{kg}$, respectively. These doses align within the range of the estimated daily intakes of humans (Heudorf et al., 2007) and, interestingly, are even below some of the tolerable daily intakes of some governing organizations (Koch et al., 2003). However, there are limitations to translating these doses of phthalates from rats to the human population due to the lack of information on interspecies differences in the toxicokinetics and their associated doseresponse relationships.

\section{Behavioral testing: attentional set-shift}

Apparatus. The attentional set-shift apparatus was a plus maze in a relatively small room with dim, indirect lighting. The center of the maze was $10 \times 10 \mathrm{~cm}$, with four equiangular arms of $10 \mathrm{~cm}$ width and $45 \mathrm{~cm}$ length. The entire maze was enclosed with $15-\mathrm{cm}$-high walls and placed upon a spinning table to allow easy adjustment during testing. The inside walls and floor of two adjacent arms were white, whereas the other two were black; and the floor of one black arm and adjacent white arm were smooth, whereas the other two were textured (i.e., "rough"). At the end of each arm, there were food troughs. For training and testing, a wallpiece could be slid into one of four positions to convert the plus-shaped maze into a T-shaped maze, blocking off entry into a specific arm.

Protocol. The attentional set shift protocol began in adulthood at $\sim$ P92, at which time rats were food restricted in preparation for testing (similar to Willing and Wagner, 2016). Throughout the 13 day protocol, rats were weighed daily and food restricted to $85 \%-90 \%$ of free-feeding 

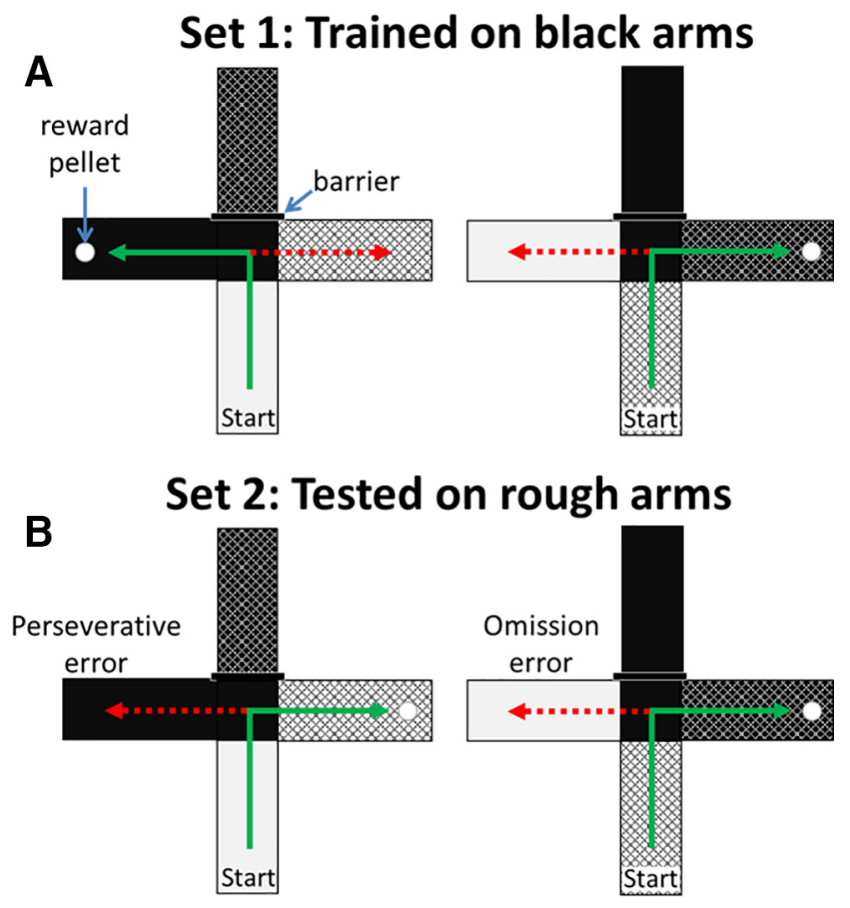

Figure 1. Attentional set-shift task. In this example, $(\boldsymbol{A})$ a rat is trained to go to black arms in Set 1. Once 8 consecutive trials of correct responses is reached, the rat is removed and is tested in Set 2 the following day. $\boldsymbol{B}$, In Set 2, the rat is tested with an extradimensional shift in the rewarding cue, such that rough arms are now baited with a reward pellet. Green arrows indicate correct responses. Red arrows indicate incorrect responses.

body weight by testing days (i.e., days 12 and 13). On days 1-5, rats were handled for $1 \mathrm{~min}$, then given 3 or 4 reward pellets (TestDiet) in their home cages. On days $6-8$, rats underwent a daily habituation trial consisting of being placed in the center of the plus-shaped maze with all four arms baited with a reward pellet. A habituation trial ended upon obtaining all four reward pellets or if $5 \mathrm{~min}$ had elapsed. On days 9-11, rats underwent 8 daily trials of pretraining. For each trial, the rat was placed at the end of one arm (start arm) with the opposing arm blocked off and learned to leave the start arm to enter only one of two open arms of the $\mathrm{T}$-shaped maze to potentially obtain a food reward. Trials were rewarded $50 \%$ of the time, and the starting arm was quasi-randomly changed on each trial to ensure no learned arm preference. On days 13 and 14, testing on Sets 1 and 2 began, respectively. The trials in both sets were similarly arranged as in pretraining trials, such that the rats were placed in alternating start arms with the option to enter only one of two target arms. Upon food restriction, estrous cycles from a subset of females were determined daily via vaginal lavage and cytology. Most females were in diestrus at the time of testing in Set 1 and Set 2, such that the stage of the estrous cycle did not have any influence on performance within the attentional set-shifting task.

Set 1: training. Rats were trained to enter a target arm using a specific cue based on color (i.e., white or black; Rule 1) to obtain a food reward (Fig. 1A), and Set 1 concluded when a performance criterion of 8 consecutively correct trials was met. Rats unable to reach this criterion within 120 trials or due to lack of motivation for a food reward were excluded from the study. Consequently, there were 9, 8, and 10 females in the respective 0,200 , and $1000 \mu \mathrm{g} / \mathrm{kg}$ groups, and there were 9,8 , and 11 males in the respective exposure groups. The total number of trials performed to reach criterion were analyzed.

Set 2: test on an extradimensional shift. On the next day after Set 1, the contingency for the reward was changed to a different sensory modality, such that rats were now trained to enter a target arm using a cue based on texture (i.e., smooth or rough; Rule 2) to obtain a food reward. This extradimensional, or cross-modal, shift is one form of behavioral flexibility that is mediated by cognitive functions of the PFC (Ragozzino et al., 1999). Rats completed 80 trials in Set 2 regardless of performance. On any given trial in Set 2, there is only one correct choice and one incorrect choice, with incorrect choices being perseverative errors or omission errors. A perseverative error is entering an incorrect arm according to the rule from Set 1, whereas an omission error is an incorrect choice that does not follow the rewarded stimuli from either set (Fig. 1B). For example, a rat is trained to receive a reward pellet on trials of Set 1 if a white arm is chosen and on trials of Set 2 if a rough arm is chosen, then a perseveration error is going to a white smooth arm during Set 2. Whether a rat performed a correct choice or an error across the 80 trials was analyzed, as well as separate analyses of perseverative and omission errors across their respective 40 trials.

\section{Neuroanatomy}

Histological preparation. Brains were collected from littermates of the animals tested in the attentional set shift task. These rats were between P103 and P134, which was at least 2 weeks after they completed behavioral tasks that did not involve food restriction: prepulse inhibition, open field, and object recognition (not reported). Rats were deeply anesthetized with sodium pentobarbital before a transcardial perfusion with 0.1 м PBS followed by 4\% PFA fixative solution. The brains were removed and stored in the PFA fixative solution for $24 \mathrm{~h}$ followed by being stored in a $30 \%$ sucrose (cryoprotectant) solution for $3 \mathrm{~d}$. At this time, brains were coded to keep the experimenter blind to the rat's group. After $3 \mathrm{~d}$ in the sucrose solution, the brain was sliced with a freezing microtome into $40 \mu \mathrm{m}$ coronal slices. One brain from a vehicle-exposed $(0 \mu \mathrm{g} / \mathrm{kg})$ female did not fix properly. Thus, there were 10, 9 , and 11 females in the respective 0,200 , and $1000 \mu \mathrm{g} / \mathrm{kg}$ groups and 11, 9, and 11 males in the respective exposure groups.

Methylene Blue/Azure II. To precisely visualize the rostral and caudal borders of the mPFC, every section at the rostral start of the frontal white matter and the caudal end in which the genu corpus callosum appears were mounted on gelatin-coated slides. For the rest of the mPFC, every fifth section was mounted with the remaining sections placed in a storage solution (30\% glycerol, $30 \%$ ethylene glycol, $30 \%$ distilled water, $10 \%$ $0.1 \mathrm{M}$ PBS) and stored in a $-20^{\circ} \mathrm{C}$ freezer for later use. Mounted sections were allowed to dry before being stained with Methylene Blue/Azure II, a cell body stain used for cellular quantification, laminar parcellation, and volume determination. Sections on a slide were covered with Permount and a coverslip.

Immunohistochemistry for synaptophysin. Three mPFC sections representative of each brain were selected from the storage solution and stained for synaptophysin, a presynaptic vesicle protein used as a marker of synapses as in Drzewiecki et al. (2016). Sections were rinsed 3 times for 5 min in TBS, pH 7.6, placed for $30 \mathrm{~min}$ in a blocking solution $(20 \%$ normal goat serum, $1 \%$ BSA, $1 \%$ hydrogen peroxide), and then incubated for $48 \mathrm{~h}$ at $4^{\circ} \mathrm{C}$ in the primary antibody (antisynaptophysin, 1:5000, Sigma-Aldrich; mouse monoclonal), which was diluted in Tris-Triton goat (TTG) solution ( $2 \%$ normal goat serum, $0.3 \%$ Triton X-100 in TBS). Following primary incubation, sections were rinsed 3 times for 5 min each in TTG followed by incubation with the biotinylated secondary antibody diluted in TTG (anti-mouse IgG antibody, $5 \mu \mathrm{g} / \mathrm{ml}$, Vector Laboratories) for $90 \mathrm{~min}$ at room temperature $\left(\sim 23^{\circ} \mathrm{C}\right)$. Sections were then rinsed for $5 \mathrm{~min}$ twice in TTG and twice in TBS. Following rinsing, sections were placed in avidin-biotin complex (Vectastain ABC Kit, Vector Laboratories) for $1 \mathrm{~h}$ at room temperature $\left(\sim 23^{\circ} \mathrm{C}\right)$ and then stained with DAB (Sigma-Aldrich Fast 3-3'Diaminobenzidine Tablets) for 2 min. Last, sections were rinsed thoroughly with TBS, mounted on gelatin-coated slides, and dried for at least $24 \mathrm{~h}$ before being coverslipped using Permount.

Volume of the mPFC. Sections stained with Methylene Blue/Azure II were used in determining the volume of the $\mathrm{MPFC}$, as previously detailed by Markham et al. (2007). The area and thickness of layers I, II/III, and V/VI were separately used to calculate the volume of the mPFC. The subcortical white matter within the $\mathrm{mPFC}$ sections was also parcellated for volume estimations.

The mPFC, which contains the prelimbic (PL) and infralimbic (IL) regions, were parcellated in reference to the underlying white matter and in accordance to cytoarchitectonic criteria (Van Eden and Uylings, 1985). Parcellation of the rostral mPFC began with the appearance of 


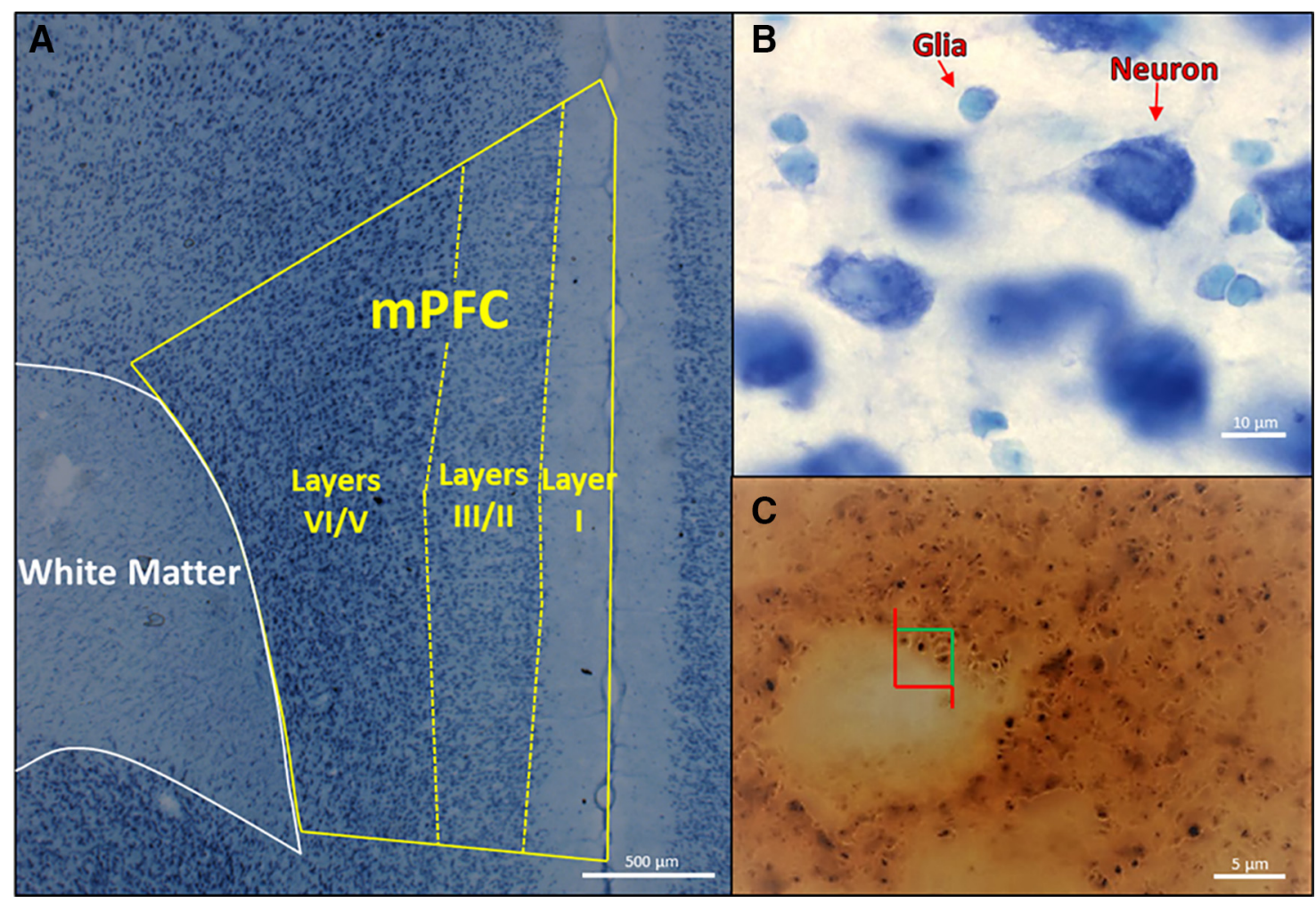

Figure 2. A, Parcellation of layers I, II/III, and V/VI of the mPFC, as well as the underlying white matter, in a Methylene Blue/Azure Il section. $\boldsymbol{B}$, Higher magnification of a Methylene Blue/Azure II section in which neurons can easily be distinguished from glia. C, High magnification of an immunohistochemically stained section of synaptophysin, a marker of synapses. The counting frame has green inclusion and red exclusion lines for stereological counting.

frontal white matter, and the caudal end of the mPFC coincided with the appearance of the genu of the corpus callosum. The dorsal border of the mPFC was identified by a decrease in layer I size, a less distinct layer I/II border, an increase in the cellular density of layer III, and a broadening of layer V/VI. The ventral border of the mPFC was identified by a loss in laminar distinction, a decrease in layer I size, and a tapering of layer V/VI.

Neuron and glia counts. The number of neurons and glia were stereologically counted with the optical disector in the sections stained with Methylene Blue/Azure II using StereoInvestigator software (Microbrightfield). After parcellating the mPFC into layers I, II/III, and V/VI (Fig. 2A), the software randomly sampled sites to count within each region. A $35 \times 35 \times 10 \mu \mathrm{m}$ (width $\times$ height $\times$ depth) counting frame was used with $1 \mu \mathrm{m}$ guard zones at the top and bottom of each section. The experimenter counted cells only if the bottom of the cell was within the volume of the counting frame. By using Methylene Blue/Azure II, neurons and glia are distinguished based upon differences in size, color, and shape. In particular, neurons are larger and are stained dark blue with a distinct nucleus and nucleolus, whereas glia are smaller, turquoisestained, amorphous cells (Fig. 2B). Given the sparse distribution of cells in layer I, cells were not quantified in this region. However, in each layers II/III and V/VI, a minimum of 150 glia and 200 neurons were counted across sampled sites of at least two sections of the mPFC from a given brain. Separate neuronal and glial densities were calculated for each lamina. These densities were multiplied by their respective laminar volumes to estimate the total number of neurons and glia.

Synapse quantification. Like the quantification previously described by Drzewiecki et al. (2016) and similar to how neurons and glia were counted above, a minimum of 200 synaptophysin-stained boutons were stereologically counted in each laminar region I, II/III, and V/VI of a given brain (Fig. 2C). In contrast to the cell counts, a $4 \times 4 \times 6 \mu \mathrm{m}$ counting frame was used with $0.1 \mu \mathrm{m}$ guard zones at the top and bottom of each section. Synaptophysin-stained bouton densities for each laminar group (i.e., I, II/III, and V/VI) were calculated. These densities were then multiplied by their respective laminar volumes to estimate the total number of synaptophysin-stained boutons.
Experimental design and statistical analyses

Using SPSS (IBM), the analysis of all neuroanatomical measures was performed using a two-way ANOVA (phthalate exposure $\times$ sex) with cohort as a cofactor. For the behavioral analysis of Set 1 of attentional set-shift, Rule 1 (i.e., the rewarding cue: black or white) was used as another cofactor in the two-way ANOVA. For Set 2, given that the dependent variable is repeatedly measured with a binary outcome (i.e., correct or incorrect), a logistic regression was used (Parzen et al., 2011), particularly within a generalized linear mixed model with trial as the repeated measure within each rat subject and phthalate exposure, sex, cohort, and Rule 1 as (co)factors. Post hoc tests were performed using Fisher's least square difference method with each phthalate exposure dose (200 and $1000 \mu \mathrm{g} / \mathrm{kg})$ only compared with the vehicle-exposed $(0$ $\mu \mathrm{g} / \mathrm{kg}$ ) group. Two-tailed correlations were run between neuroanatomical measures and indices of attentional set shift performance for rats within the same litter. Data are mean \pm SEM.

\section{Results}

\section{Attentional set-shift}

Set 1: training

There was no effect of phthalate exposure, but stimulus $\left(F_{(1,44)}=\right.$ 18.545, $p<0.001)$ and sex $\left(F_{(1,44)}=4.569, p=0.038\right)$ were significant for trials to criterion, such that rats with black arms reached criterion sooner than rats with white arms as the rewarding cue and male rats reached criterion sooner than female rats (Fig. 3).

\section{Set 2: extradimensional shift}

For correct responses, there was a significant effect of phthalate exposure $\left(F_{(2,4389)}=6.195, p=0.002\right)$, such that vehicle-exposed rats performed significantly better than both the relatively low $(p=0.001)$ and high phthalate-exposed rats $(p=0.019)$. Additionally, there was a significant effect of $\operatorname{sex}\left(F_{(1,4389)}=10.665\right.$, 


\section{Set 1: Training}

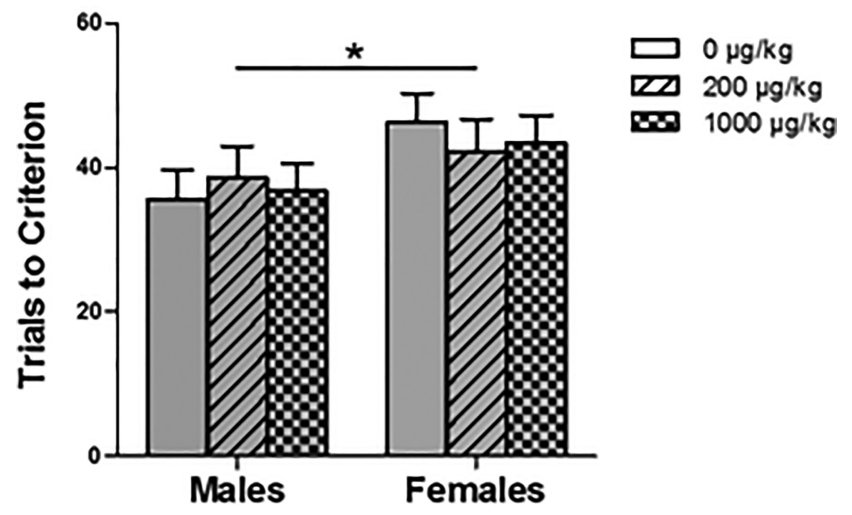

Figure 3. Performance on the black/white discrimination in Set 1 of attentional set-shift. Males performed significantly better than females $\left({ }^{*} p=0.038\right)$, but there were no effects of phthalate exposure. From left to right on the $x$-axis: 0,200 , and $1000 \mu \mathrm{g} / \mathrm{kg}$ males followed by the respective female groups; $n=9, n=8, n=11, n=9, n=8$, and $n=$ 10 , respectively.

$p=0.001)$, such that males performed significantly better than females (Fig. 4A).

For perseverative errors, there was a significant effect of phthalate exposure $\left(F_{(2,2189)}=3.526, p=0.030\right)$, such that vehicle-exposed rats had significantly fewer perseverative errors than the relatively low phthalate-exposed rats $(p=0.009)$. There was also a significant effect of $\operatorname{sex}\left(F_{(1,2189)}=10.665, p=0.002\right)$, such that males performed significantly fewer perseverative errors than females (Fig. $4 B$ ).

For omission errors, there was only a significant effect of phthalate exposure $\left(F_{(2,2189)}=5.159, p=0.006\right)$, such that vehicle-treated rats had significantly fewer omission errors than both the relatively low $(p=0.004)$ and high phthalate-exposed rats $(p=0.010)$ (Fig. $4 C)$

\section{Neuroanatomy}

Neurons and glia

The number of neurons in the MPFC was decreased by perinatal phthalate exposure $\left(F_{(2,51)}=23.834, p<0.001\right)$ at both doses $(p<0.001)$ (Fig. 5A). The phthalate exposure effect on neuron number was evident in both layers II/III $\left(F_{(2,51)}=21.891, p<\right.$ $0.001)$ and V/VI $\left(F_{(2,51)}=18.879, p<0.001\right)$. Additionally, the number of neurons in the mPFC was greater in males than in females $\left(F_{(1,51)}=9.167, p=0.004\right)$, and this occurred in both layers II/III $\left(F_{(1,51)}=6.931, p=0.011\right)$ and V/VI $\left(F_{(1,51)}=8.703\right.$, $p=0.005)$, similar to previous work in our laboratory (Markham et al., 2007).

There were no effects of phthalate exposure on the number of glia in total or in each lamina (Fig. 5B). There was a significant sex difference $\left(F_{(1,51)}=7.012, p=0.011\right)$, indicating that males had more glia in the mPFC than females, as in Markham et al. (2007). Although males had numerically more glia than females in both laminar groups, it was only significant in layers II/III $\left(F_{(1,51)}=\right.$ $11.728, p=0.001)$ and not in layers $\operatorname{V} / \mathrm{VI}\left(F_{(1,51)}=3.351\right.$, $p=0.073)$.

Synaptophysin: marker of synapses

Analysis of the total number of synaptophysin boutons in the mPFC revealed a significant effect of phthalate exposure $\left(F_{(2,51)}=6.041, p=0.004\right)$, such that vehicle-exposed rats had significantly more synapses in the mPFC than both the relatively low $(p=0.011)$ and high phthalate-exposed rats $(p=0.002)$
(Fig. 6A). This phthalate exposure effect was evident in layers II/III $\left(F_{(2,51)}=3.936, p=0.026\right)$ and V/VI $\left(F_{(2,51)}=11.053, p<\right.$ $0.001)$, but not in layer I $\left(F_{(2,51)}=1.771, p=0.180\right)$. Additionally, there was a significant effect of $\operatorname{sex}\left(F_{(1,51)}=5.873, p=\right.$ $0.019)$, indicating that males had significantly more synapses in the mPFC than females. Although there was a numerical difference between the sexes in each of the laminar groups, it was significant only in layers V/VI $\left(F_{(1,51)}=7.754, p=0.008\right)$ and not in layer I $\left(F_{(1,51)}=3.498, p=0.067\right)$ or layers II/III $\left(F_{(1,51)}=\right.$ $3.674, p=0.061)$. Last, there were no significant effects for the number of synaptophysin-labeled synapses per neuron (Fig. 6B).

$m P F C$ and underlying white matter volume

Overall, there was a significant effect of phthalate exposure $\left(F_{(2,51)}=5.207, p=0.009\right)$ on the total volume of the mPFC (Fig. $7 A)$, such that the vehicle-exposed rats had larger volumes than both the relatively low $(p=0.027)$ and high phthalate-exposed rats $(p=0.003)$. This effect was significant in layers $\mathrm{I}\left(F_{(2,51)}=\right.$ $3.312, p=0.044)$ and V/VI $\left(F_{(2,51)}=8.219, p=0.001\right)$, but not in layers II/III $\left(F_{(2,51)}=2.943, p=0.062\right)$. Additionally, there was a significant effect of sex $\left(F_{(1,51)}=11.993, p=0.001\right)$, with males having larger volumes compared with females, as in previous work (Markham et al., 2007). This sex difference was significant in each laminar group: layer $\mathrm{I}\left(F_{(1,51)}=20.477, p<0.001\right)$, layers $\mathrm{II} / \mathrm{III}\left(F_{(1,51)}=8.680, p=0.005\right)$, and layers V/VI $\left(F_{(1,51)}=8.293\right.$, $p=0.006)$.

There was no effect of phthalate exposure on the volume of the white matter under the mPFC (Fig. $7 B$ ), but there was, as expected (Markham et al., 2007), a significant sex difference $\left(F_{(1,51)}=10.665, p=0.002\right)$, indicating that males had larger white matter volumes than females.

\section{Neuroanatomy-behavior correlations}

The number of synaptophysin boutons was significantly, and positively, correlated with the number of correct choices in Set 2 of the attentional set shift task $(r=0.291, p=0.033)$, such that rats of littermates with more boutons in the mPFC performed better than those of littermates with fewer. Although not significant, total synaptophysin boutons showed a trend toward a negative correlation with the total perseverative errors in Set 2 of the attentional set shift task $(r=-0.243, p=0.076)$. These findings were most prominent in the last 40 trials of Set 2 (i.e., the second half) when performance was generally better, such that rats with more synaptophysin boutons performed better on the task than those with fewer, as assessed by total correct choices $(r=0.327$, $p=0.016)$ and perseverative errors $(r=-0.302, p=0.027$; Table $1)$. There were no correlations between the behavioral measures and either neurons or glia.

\section{Discussion}

The present study found that perinatal exposure to phthalates resulted in decreased cognitive flexibility and a lower number of neurons and synapses in the mPFC in adulthood across both sexes. Interestingly, the number of synapses within the mPFC also correlated with measures of cognitive flexibility, such that littermates of rats with fewer synapses demonstrated less cognitive flexibility than those of littermates with more synapses. The lack of phthalate effects on the number of synapses per neuron indicates that the primary influence of phthalates may be on neuron number itself. However, it is also possible that the loss of neurons and loss of synapses are separate, interdependent effects. In contrast to the decreased number of neurons, there were no effects of phthalate exposure on the number of glia in the mPFC, so that not all cells decreased despite the reduced volume of the mPFC. It is 


\section{Set 2: Cognitive Flexibility}

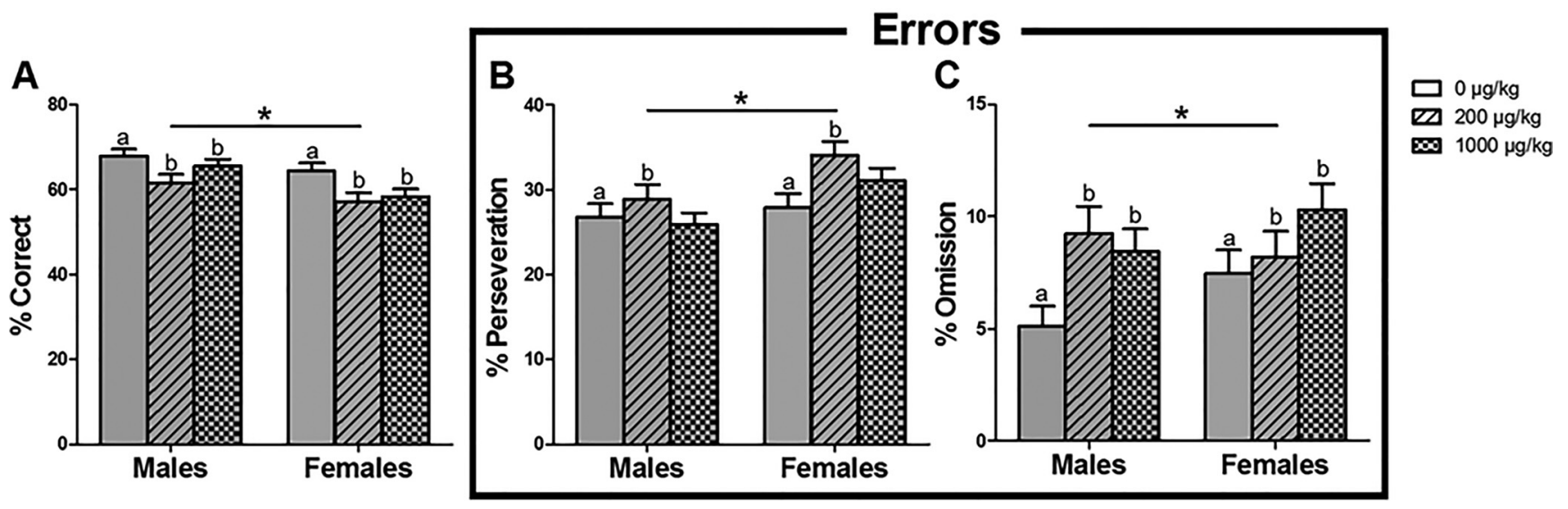

Figure 4. Performance on the extradimensional shift (Set 2) as assessed by $(\boldsymbol{A})$ percentage correct, $(\boldsymbol{B})$ perseverative errors, and $(\boldsymbol{C})$ omission errors across 80 trials in Set 2 of attentional set-shift Overall, there were phthalate exposure effects $(p \leq 0.030)$, such that both the low and high phthalate-exposed rats performed significantly worse on this task compared with vehicle-exposed rats. Additionally, males performed significantly better than females, as indicated by more correct responses $\left({ }^{*} p=0.001\right)$ and fewer perseverative errors $\left({ }^{*} p=0.002\right)$. From left to right on the $x$-axis of each measurement: 0,200 , and $1000 \mu \mathrm{g} / \mathrm{kg}$ males followed by the respective female groups; $n=9, n=8, n=11, n=9, n=8$, and $n=10$, respectively. a and b indicate groups that are significantly different.

A

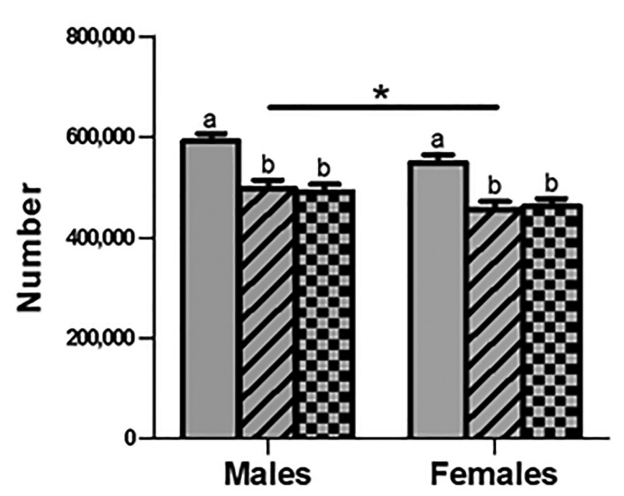

B

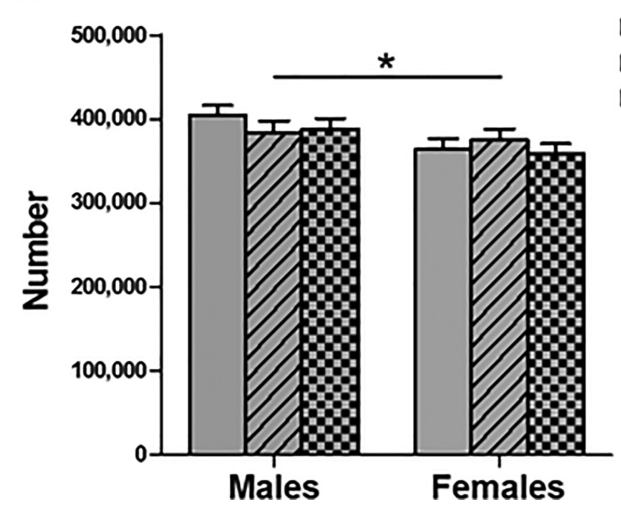

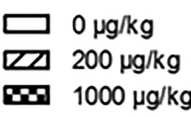

$1000 \mu \mathrm{g} / \mathrm{kg}$

Figure 5. Total number of neurons $(\boldsymbol{A})$ and glia $(\boldsymbol{B})$ in the mPFC. Vehicle-exposed rats across both sexes had more neurons in the $\mathrm{mPFC}(\mathrm{a}>\mathrm{b})$ than the relatively low $(p<0.001)$ and high phthalate-exposed rats $(p<0.001)$. Additionally, males had more neurons $\left({ }^{*} p=0.004\right)$ and glia $\left({ }^{*} p=0.011\right)$ in the $m P F C$ than females. From left to right on the $x$-axis for total number of neurons and glia in the mPFC: 0,200 , and $1000 \mu \mathrm{g} / \mathrm{kg}$ males followed by the respective female groups; $n=11, n=9, n=11, n=10, n=9$, and $n=11$, respectively.

possible that the lack of a phthalate effect on glia and the underlying white matter is due to the high capacity of glia, and thus myelin, to regenerate (Hattori et al., 1989; Askew et al., 2017).

The present study indicates that perinatal exposure to an environmentally relevant mixture of phthalates resulted in a longterm deficit in cognitive flexibility rather than general learning ability, such that phthalate-exposed male and female rats performed worse on the extradimensional shift, but not on the initial discrimination training. Although cognitive flexibility, to our knowledge, has never been directly examined following perinatal phthalate exposure in either rodents or humans, perinatal phthalate exposure in humans has been associated with symptoms related to autism spectrum disorder and attention deficit hyperactivity disorder, disorders with reduced cognitive flexibility (Etchepareborda and Mulas, 2004; Lai et al., 2017).

The phthalate-induced deficit in cognitive flexibility was not mediated by alterations in maternal care, as we have previously reported no effects of this phthalate mixture on maternal behavior (Kougias et al., 2018). However, based on our litter-specific correlations, it appears that this phthalate-induced deficit in cog- nitive flexibility may be mediated by phthalate-induced neuroanatomical changes. It is not clear why the total number of synapses, but not the number of neurons, correlated with behavior. However, considering that lesions outside of the $\mathrm{mPFC}$ are known to alter dendritic complexity and spine density within the mPFC (for review, see Kolb and Gibb, 2015), perhaps there are changes in other brain regions that are driving this deficit in behavior, such that synapses more appropriately reflect the perturbed circuitry. In support of this, a stress-induced decrease in dendritic arborization in the MPFC has been shown to be predictive of impaired performance in an attentional set-shifting task (Liston et al., 2006).

Interestingly, congruent with the behavioral effects of perinatal phthalate exposure, neonatal lesions of the rat mPFC have been shown to decrease cognitive flexibility in adulthood without affecting working memory (Schwabe et al., 2004; Schneider and Koch, 2005a). Moreover, neonatal lesions of the rat mPFC have been shown to disrupt periadolescent social play (Schneider and Koch, 2005b), which is consistent with what we previously reported following perinatal exposure to an identical phthalate 


\section{A}

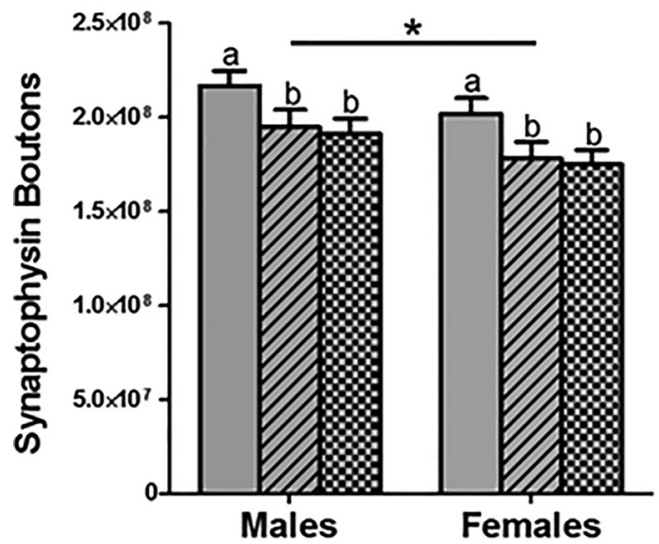

B

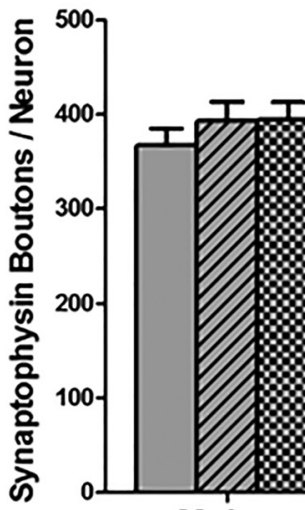

Males

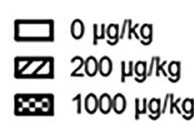

Figure 6. Total number of synaptophysin boutons $(\boldsymbol{A})$, a marker of synapses, and $(\boldsymbol{B})$ synapses per neuron in the mPFC. Vehicle-exposed rats across both sexes had more synaptophysin boutons in the mPFC than the relatively low $(p=0.011)$ and high phthalate-exposed rats $(p=0.002)(\mathrm{a}>\mathrm{b})$. Males had more synaptophysin boutons in the $\mathrm{mPFC}$ than females $\left({ }^{*} p=0.019\right)$. From left to right on the $x$-axis for total number of synapses and synapses per neuron in the $\mathrm{mPFC}: 0,200$, and $1000 \mu \mathrm{g} / \mathrm{kg}$ males followed by the respective female groups; $n=11, n=9, n=11, n=10$, $n=9$, and $n=11$, respectively.
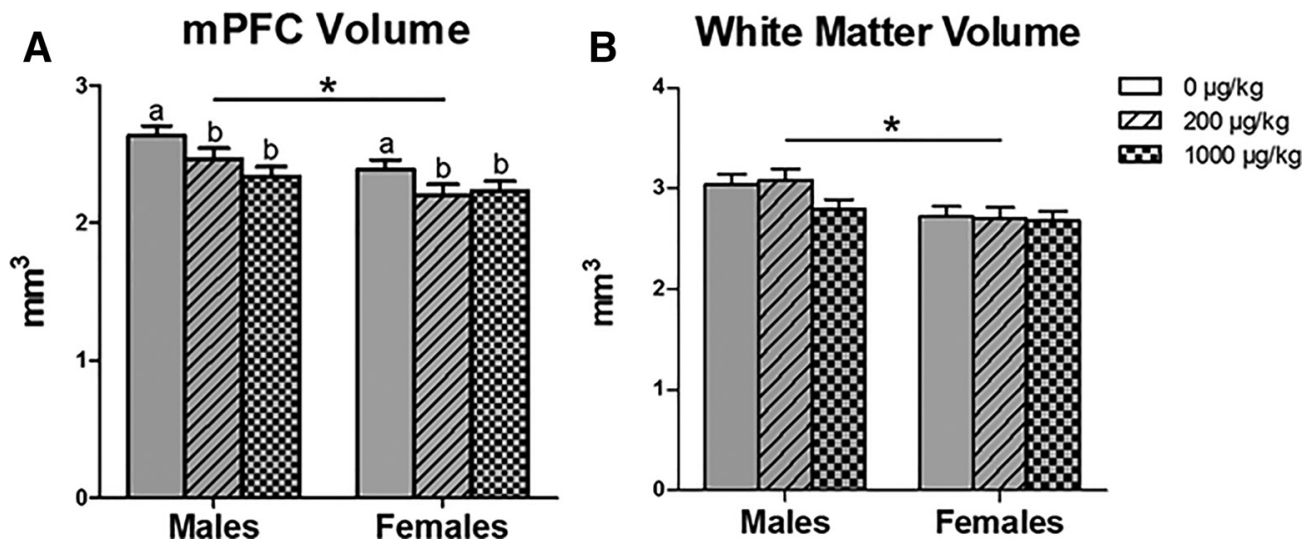

Figure 7. Volume of the $\operatorname{mPFC}(\boldsymbol{A})$ and underlying white matter $(\boldsymbol{B})$. Vehicle-exposed rats across both sexes had larger mPFC volumes than the relatively low $(p=0.027)$ and high phthalateexposed rats $(p=0.003)(\mathrm{a}>\mathrm{b})$. Additionally, males had larger mPFC $\left({ }^{*} p=0.001\right)$ and white matter volumes $\left({ }^{*} p=0.002\right)$ than females. From left to right on the $x$-axis for the volume of the $\mathrm{mPFC}$ and the underlying white matter: $0,200,1000 \mu \mathrm{g} / \mathrm{kg}$ males followed by the respective female groups; $n=11, n=9, n=11, n=10, n=9$, and $n=11$, respectively.

Table 1. Neuroanatomy-behavior correlations ${ }^{a}$

\begin{tabular}{|c|c|c|c|c|}
\hline \multirow[b]{3}{*}{ Neuroanatomy } & \multicolumn{4}{|c|}{ Cognitive flexibility } \\
\hline & \multicolumn{2}{|l|}{ Correct choices } & \multicolumn{2}{|l|}{ Perseveration } \\
\hline & All 80 trials & Last 40 trials & All 80 trials & Last 40 trials \\
\hline Synaptophysin & $\begin{array}{l}R=0.291 \\
p=0.033^{*}\end{array}$ & $\begin{array}{l}R=0.327 \\
p=0.016^{*}\end{array}$ & $\begin{array}{l}R=-0.243 \\
p=0.076\end{array}$ & $\begin{array}{l}R=-0.302 \\
p=0.027^{*}\end{array}$ \\
\hline Neurons & $\begin{array}{l}R=-0.018 \\
p=0.895\end{array}$ & & $\begin{array}{l}R=0.071 \\
p=0.607\end{array}$ & \\
\hline Glia & $\begin{array}{l}R=-0.035 \\
p=0.803\end{array}$ & & $\begin{array}{l}R=0.007 \\
p=0.963\end{array}$ & \\
\hline
\end{tabular}

${ }^{a}$ Correlations (Pearson's coefficient $R, p$ value) between measurements of neuroanatomy and measures of cognitive flexibility $(n=55)$.

*Significant.

mixture (Kougias et al., 2018). Together, this suggests that phthalates have neurotoxic effects on the developing mPFC, especially in light of the decreased number of neurons and synapses found in the current study in response to phthalate exposure.

Additionally, males learned the initial cue (i.e., training) and the extradimensional shift (i.e., cognitive flexibility) more quickly than females. This is broadly consistent with the literature, as sex differences in several learning and memory tasks have been reported in rats (Jonasson, 2005). Furthermore, it is well established that exposure to an acute stressful event can produce, or magnify, sex differences in learning and memory (for review, see Shors, 2004), as well as in behavioral flexibility (for review, see Hurtubise and Howland, 2017), but whether stressful events can generalize to mild food restriction is not well studied. However, Rajab et al. (2014) has demonstrated that $2 \mathrm{~h}$ of food restriction has a negative impact on water maze performance in females, but a positive influence in males. Thus, it is possible that the sex differences in cognitive performance found in this study were accentuated with food restriction.

As a class of endocrine-disrupting chemicals, phthalates have a promiscuous set of mechanistic actions that are specific to each phthalate and to the various metabolites (e.g., Chauvigné et al., 2009). Collectively, though, phthalates are known to have antiandrogenic, estrogenic, and antiestrogenic activity (Takeuchi et al., 2005); but given that both sexes were similarly affected by perinatal exposure, phthalates may not be disrupting gonadal steroid effects on sexual differentiation. Although there are indications that neonatal androgens can affect apoptosis in the visual cortex (Nuñez et al., 2000), whether there is a role for sex hormones in the perinatal development of the mPFC is not known. 
Rather, the ovarian hormones secreted at puberty are the major influence on the sex difference in neuron number in the mPFC (Koss et al., 2015). Furthermore, there are mixed data regarding this mixture's antiandrogenic potential reported by Kougias et al. (2018) where the mixture at either dose did not significantly affect anogenital distance, a reliable marker for prenatal androgen exposure, in either males or females. However, periadolescent social play, which is known to be positively influenced by neonatal androgens, was shown to be decreased at the lower dose, especially in males. Additionally, a similar mixture of five phthalates showed no antiandrogenic activity in vitro (Christen et al., 2012). Therefore, it is difficult to ascribe our results to disrupted gonadal hormones or to speculate on a collective toxicodynamic effect given the erratic nature of phthalate mixtures.

Moreover, phthalates can have such wide-ranging effects as repressing the synthesis of steroidogenic enzymes (Kim et al., 2004; David, 2006), weakly antagonizing cannabinoid receptors (Bisset et al., 2011), suppressing calcium signaling in nicotinic receptors (Liu et al., 2009), and interfering with thyroid (Boas et al., 2012), IGF-1 (Boas et al., 2010), and insulin signaling (Huang et al., 2014; Smerieri et al., 2015). In vitro phthalate exposure can also induce apoptosis in murine neurons (Lin et al., 2011), potentially in a hormone-independent manner (Wójtowicz et al., 2017), and can perhaps suppress cell proliferation (Chen et al., 2011). Thus, there are several potential mechanisms for how phthalates could have affected neuron number, but more detailed conclusions cannot be specified at this time.

Regardless of the mechanistic action of this phthalate mixture, the present neuroanatomical results complement the current literature on exposure to a single phthalate; however, our study, for the first time, shows a long-lasting neuroanatomical change. Previous studies on perinatal exposure to a single phthalate have demonstrated that phthalates can impair functional plasticity of hippocampal circuits and related behavior (for review, see Holahan and Smith, 2015). In particular, perinatal exposure to DBP at a very high dose $(500 \mathrm{mg} / \mathrm{kg})$ in rats has been shown to decrease synaptophysin within the hippocampus of both males and females immediately after exposure at P21, but this effect was not significant at P60 (Li et al., 2013). Additionally, prenatal exposure to DEHP has also been shown to result in abnormal neuronal distribution and reduced neuronal number at P7 in the cortex of mice (Komada et al., 2016); however, it is unclear which part of the cortex was investigated. Further research is needed to determine the mechanism underlying these neurotoxic effects of a mixture of phthalates.

Overall, this study is unique in showing that perinatal exposure to an environmentally relevant mixture of phthalates had long-term effects on the mPFC neuroanatomy and behavior of adult rats. These effects were independent of sex, suggesting a common neurotoxic effect of phthalates in the developing cortex of males and females. Furthermore, these effects were seen at both doses of the phthalate mixture, which were relatively low compared with the existing rodent literature and are presumably within the range of the estimated daily intakes of humans. Thus, these results may have serious implications for humans given that $\mathrm{mPFC}$ is involved in executive functions and is implicated in the pathology of many neuropsychiatric disorders.

\section{References}

Askew K, Li K, Olmos-Alonso A, Garcia-Moreno F, Liang Y, Richardson P, Tipton T, Chapman MA, Riecken K, Beccari S, Sierra A, Molnár Z, Cragg MS, Garaschuk O, Perry VH, Gomez-Nicola D (2017) Coupled proliferation and apoptosis maintain the rapid turnover of microglia in the adult brain. Cell Rep 18:391-405. CrossRef Medline
Bisset KM, Dhopeshwarkar AS, Liao C, Nicholson RA (2011) The G protein-coupled cannabinoid-1 (CB1) receptor of mammalian brain: inhibition by phthalate esters in vitro. Neurochem Int 59:706-713. CrossRef Medline

Boas M, Frederiksen H, Feldt-Rasmussen U, Skakkebæk NE, Hegedüs L, Hilsted L, Juul A, Main KM (2010) Childhood exposure to phthalates: associations with thyroid function, insulin-like growth factor I, and growth. Environ Health Perspect 118:1458-1464. CrossRef Medline

Boas M, Feldt-Rasmussen U, Main KM (2012) Thyroid effects of endocrine disrupting chemicals. Mol Cell Endocrinol 355:240-248. CrossRef Medline

Chauvigné F, Menuet A, Lesné L, Chagnon MC, Chevrier C, Regnier JF, Angerer J, Jégou B (2009) Time- and dose-related effects of di-(2ethylhexyl) phthalate and its main metabolites on the function of the rat fetal testis in vitro. Environ Health Perspect 117:515-521. CrossRef Medline

Chen T, Yang W, Li Y, Chen X, Xu S (2011) Mono-(2-ethylhexyl) phthalate impairs neurodevelopment: inhibition of proliferation and promotion of differentiation in PC12 cells. Toxicol Lett 201:34-41. CrossRef Medline

Christen V, Crettaz P, Oberli-Schrämmli A, Fent K (2012) Antiandrogenic activity of phthalate mixtures: validity of concentration addition. Toxicol Appl Pharmacol 259:169-176. CrossRef Medline

Corbasson I, Hankinson SE, Stanek EJ 3rd, Reeves KW (2016) Urinary bisphenol-A, phthalate metabolites and body composition in US adults, NHANES 1999-2006. Int J Environ Health Res 26:606-617. CrossRef Medline

Dai Y, Yang Y, Xu X, Hu Y (2015) Effects of uterine and lactational exposure to di-(2-ethylhexyl) phthalate on spatial memory and NMDA receptor of hippocampus in mice. Horm Behav 71:41-48. CrossRef Medline

David RM (2006) Proposed mode of action for in utero effects of some phthalate esters on the developing male reproductive tract. Toxicol Pathol 34:209-219. CrossRef Medline

DeBartolo D, Jayatilaka S, Yan Siu N, Rose M, Ramos RL, Betz AJ (2016) Perinatal exposure to benzyl butyl phthalate induces alterations in neuronal development/maturation protein expression, estrogen responses, and fear conditioning in rodents. Behav Pharmacol 27:77-82. CrossRef Medline

Dostal LA, Weaver RP, Schwetz BA (1987) Transfer of di(2-ethylhexyl) phthalate through rat milk and effects on milk composition and the mammary gland. Toxicol Appl Pharmacol 91:315-325. CrossRef Medline

Drzewiecki CM, Willing J, Juraska JM (2016) Synaptic number changes in the medial prefrontal cortex across adolescence in male and female rats: a role for pubertal onset. Synapse 70:361-368. CrossRef Medline

Ejaredar M, Nyanza EC, Ten Eycke K, Dewey D (2015) Phthalate exposure and childrens neurodevelopment: a systematic review. Environ Res 142: 51-60. CrossRef Medline

Engel SM, Miodovnik A, Canfield RL, Zhu C, Silva MJ, Calafat AM, Wolff MS (2010) Prenatal phthalate exposure is associated with childhood behavior and executive functioning. Environ Health Perspect 118:565-571. CrossRef Medline

Etchepareborda MC, Mulas F (2004) Cognitive flexibility, an additional symptom of attention deficit hyperactivity disorder: is it a therapeutically predictive element? Rev Neurol 38 [Suppl 1]:S97-S102.

Forger NG (2009) Control of cell number in the sexually dimorphic brain and spinal cord. J Neuroendocrinol 21:393-399. CrossRef Medline

Gruber AJ, Calhoon GG, Shusterman I, Schoenbaum G, Roesch MR, O’Donnell P (2010) More is less: a disinhibited prefrontal cortex impairs cognitive flexibility. J Neurosci 30:17102-17110. CrossRef Medline

Hattori T, Hamada S, Masaki T, Kushima R, Ohmura M, Kataoka Y, Ikehara Y, Kita M, Magami Y (1989) Turnover of glial cells in the central nervous system. Biomed Res 10:355-363.

Heudorf U, Mersch-Sundermann V, Angerer J (2007) Phthalates: toxicology and exposure. Int J Hyg Environ Health 210:623-634. CrossRef Medline

Holahan MR, Smith CA (2015) Phthalates and neurotoxic effects on hippocampal network plasticity. Neurotoxicology 48:21-34. CrossRef Medline

Howdeshell KL, Hotchkiss AK, Gray LE Jr (2017) Cumulative effects of antiandrogenic chemical mixtures and their relevance to human health risk assessment. Int J Hyg Environ Health 220:179-188. CrossRef Medline

Huang T, Saxena AR, Isganaitis E, James-Todd T (2014) Gender and racial/ ethnic differences in the associations of urinary phthalate metabolites 
with markers of diabetes risk: national health and nutrition examination survey 2001-2008. Environ Health 13:6. CrossRef Medline

Hurtubise JL, Howland JG (2017) Effects of stress on behavioral flexibility in rodents. Neuroscience 345:176-192. CrossRef Medline

Jeddi MZ, Janani L, Memari AH, Akhondzadeh S, Yunesian M (2016) The role of phthalate esters in autism development: a systematic review. Environ Res 151:493-504. CrossRef Medline

Jonasson Z (2005) Meta-analysis of sex differences in rodent models of learning and memory: a review of behavioral and biological data. Neurosci Biobehav Rev 28:811-825. CrossRef Medline

Kim HS, Kim TS, Shin JH, Moon HJ, Kang IH, Kim IY, Oh JY, Han SY (2004) Neonatal exposure to di( $n$-butyl) phthalate (DBP) alters male reproductivetract development. J Toxicol Environ Health A 67:2045-2060. CrossRef Medline

Kobrosly RW, Evans S, Miodovnik A, Barrett ES, Thurston SW, Calafat AM, Swan SH (2014) Prenatal phthalate exposures and neurobehavioral development scores in boys and girls at 6-10 years of age. Environ Health Perspect 122:521-528. CrossRef Medline

Koch HM, Drexler H, Angerer J (2003) An estimation of the daily intake of di(2-ethylhexyl)phthalate (DEHP) and other phthalates in the general population. Int J Hyg Environ Health 206:77-83. CrossRef Medline

Kolb B, Gibb R (2015) Plasticity in the prefrontal cortex of adult rats. Frontiers in cellular neuroscience 9:15. CrossRef Medline

Komada M, Gendai Y, Kagawa N, Nagao T (2016) Prenatal exposure to di(2-ethylhexyl) phthalate impairs development of the mouse neocortex. Toxicol Lett 259:69-79. CrossRef Medline

Koss WA, Lloyd MM, Sadowski RN, Wise LM, Juraska JM (2015) Gonadectomy before puberty increases the number of neurons and glia in the medial prefrontal cortex of female, but not male, rats. Dev Psychobiol 57:305-312. CrossRef Medline

Kougias DG, Cortes LR, Moody L, Rhoads S, Pan YX, Juraska JM (2018) Effects of perinatal exposure to phthalates and a high-fat diet on maternal behavior and pup development and social play. Endocrinology 159:10881105. CrossRef Medline

Lai CL, Lau Z, Lui SS, Lok E, Tam V, Chan Q, Cheng KM, Lam SM, Cheung EF (2017) Meta-analysis of neuropsychological measures of executive functioning in children and adolescents with high-functioning autism spectrum disorder. Autism Res 10:911-939. CrossRef Medline

Li XJ, Jiang L, Chen L, Chen HS, Li X (2013) Neurotoxicity of dibutyl phthalate in brain development following perinatal exposure: a study in rats. Environ Toxicol Pharmacol 36:392-402. CrossRef Medline

Lien YJ, Ku HY, Su PH, Chen SJ, Chen HY, Liao PC, Chen WJ, Wang SL (2015) Prenatal exposure to phthalate esters and behavioral syndromes in children at 8 years of age: Taiwan maternal and infant cohort study. Environ Health Perspect 123:95-100. CrossRef Medline

Lin CH, Chen TJ, Chen SS, Hsiao PC, Yang RC (2011) Activation of Trim17 by PPARgamma is involved in di(2-ethylhexyl) phthalate (DEHP)induced apoptosis on neuro-2a cells. Toxicol Lett 206:245-251. CrossRef Medline

Liston C, Miller MM, Goldwater DS, Radley JJ, Rocher AB, Hof PR, Morrison JH, McEwen BS (2006) Stress-induced alterations in prefrontal cortical dendritic morphology predict selective impairments in perceptual attentional set-shifting. The Journal of neuroscience : the official journal of the Society for Neuroscience 26:7870-7874. CrossRef Medline

Liu PS, Tseng FW, Liu JH (2009) Comparative suppression of phthalate monoesters and phthalate diesters on calcium signalling coupled to nicotinic acetylcholine receptors. J Toxicol Sci 34:255-263. CrossRef Medline

Lyche JL, Gutleb AC, Bergman A, Eriksen GS, Murk AJ, Ropstad E, Saunders M, Skaare JU (2009) Reproductive and developmental toxicity of phthalates. J Toxicol Environ Health B Crit Rev 12:225-249. CrossRef Medline

Markham JA, Morris JR, Juraska JM (2007) Neuron number decreases in the rat ventral, but not dorsal, medial prefrontal cortex between adolescence and adulthood. Neuroscience 144:961-968. CrossRef Medline

Mose T, Knudsen LE, Hedegaard M, Mortensen GK (2007) Transplacental transfer of monomethyl phthalate and mono(2-ethylhexyl) phthalate in a human placenta perfusion system. Int J Toxicol 26:221-229. CrossRef Medline

Nishizuka M, Arai Y (1981) Organizational action of estrogen on synaptic pattern in the amygdala: implications for sexual differentiation of the brain. Brain research 213:422-426. CrossRef Medline

Nuñez JL, Jurgens HA, Juraska JM (2000) Androgens reduce cell death in the developing rat visual cortex. Brain Res Dev Brain Res 125:83-88. CrossRef Medline

Park S, Lee JM, Kim JW, Cheong JH, Yun HJ, Hong YC, Kim Y, Han DH, Yoo HJ, Shin MS, Cho SC, Kim BN (2015) Association between phthalates and externalizing behaviors and cortical thickness in children with attention deficit hyperactivity disorder. Psychol Med 45:1601-1612. CrossRef Medline

Parzen M, Ghosh S, Lipsitz S, Sinha D, Fitzmaurice GM, Mallick BK, Ibrahim JG (2011) A generalized linear mixed model for longitudinal binary data with a marginal logit link function. Ann Appl Stat 5:449-467. CrossRef Medline

Pérez J, Naftolin F, García Segura LM (1990) Sexual differentiation of synaptic connectivity and neuronal plasma membrane in the arcuate nucleus of the rat hypothalamus. Brain Res 527:116-122. CrossRef Medline

Pérez SE, Chen EY, Mufson EJ (2003) Distribution of estrogen receptor alpha and beta immunoreactive profiles in the postnatal rat brain. Brain Res Dev Brain Res 145:117-139. CrossRef Medline

Ragozzino ME, Detrick S, Kesner RP (1999) Involvement of the prelimbicinfralimbic areas of the rodent prefrontal cortex in behavioral flexibility for place and response learning. J Neurosci 19:4585-4594. CrossRef Medline

Rajab E, Alqanbar B, Naiser MJ, Abdulla HA, Al-Momen MM, Kamal A (2014) Sex differences in learning and memory following short-term dietary restriction in the rat. Int J Dev Neurosci 36:74-80. CrossRef Medline

Reagan-Shaw S, Nihal M, Ahmad N (2008) Dose translation from animal to human studies revisited. FASEB J 22:659-661. CrossRef Medline

Schneider M, Koch M (2005a) Behavioral and morphological alterations following neonatal excitotoxic lesions of the medial prefrontal cortex in rats. Exp Neurol 195:185-198. CrossRef Medline

Schneider M, Koch M (2005b) Deficient social and play behavior in juvenile and adult rats after neonatal cortical lesion: effects of chronic pubertal cannabinoid treatment. Neuropsychopharmacology 30:944957. CrossRef Medline

Schwabe K, Enkel T, Klein S, Schütte M, Koch M (2004) Effects of neonatal lesions of the medial prefrontal cortex on adult rat behaviour. Behav Brain Res 153:21-34. CrossRef Medline

Shors TJ (2004) Learning during stressful times. Learn Mem 11:137-144. CrossRef Medline

Simerly RB (2002) Wired for reproduction: organization and development of sexually dimorphic circuits in the mammalian forebrain. Annu Rev Neurosci 25:507-536. CrossRef Medline

Smerieri A, Testa C, Lazzeroni P, Nuti F, Grossi E, Cesari S, Montanini L, Latini G, Bernasconi S, Papini AM, Street ME (2015) Di-(2-ethylhexyl) phthalate metabolites in urine show age-related changes and associations with adiposity and parameters of insulin sensitivity in childhood. PLoS One 10:e0117831. CrossRef Medline

Swan SH, Liu F, Hines M, Kruse RL, Wang C, Redmon JB, Sparks A, Weiss B (2010) Prenatal phthalate exposure and reduced masculine play in boys. Int J Androl 33:259-269. CrossRef Medline

Takeuchi S, Iida M, Kobayashi S, Jin K, Matsuda T, Kojima H (2005) Differential effects of phthalate esters on transcriptional activities via human estrogen receptors alpha and beta, and androgen receptor. Toxicology 210:223-233. CrossRef Medline

Tsai HW, Taniguchi S, Samoza J, Ridder A (2015) Age- and sex-dependent changes in androgen receptor expression in the developing mouse cortex and hippocampus. Neurosci J 2015:525369. CrossRef Medline

Van Eden CG, Uylings HB (1985) Cytoarchitectonic development of the prefrontal cortex in the rat. J Comp Neurol 241:253-267. CrossRef Medline

Westberry JM, Wilson ME (2012) Regulation of estrogen receptor alpha gene expression in the mouse prefrontal cortex during early postnatal development. Neurogenetics 13:159-167. CrossRef Medline

Willing J, Wagner CK (2016) Progesterone receptor expression in the developing mesocortical dopamine pathway: importance for complex cognitive behavior in adulthood. Neuroendocrinology 103:207-222. CrossRef Medline

Wójtowicz AK, Szychowski KA, Wnuk A, Kajta M (2017) Dibutyl phthalate (DBP)-induced apoptosis and neurotoxicity are mediated via the aryl hydrocarbon receptor (AhR) but not by estrogen receptor alpha (ERalpha), estrogen receptor beta (ERbeta), or peroxisome proliferator-activated receptor gamma (PPARgamma) in mouse cortical neurons. Neurotox Res 31:7789. CrossRef Medline 